RAD Conference Proceedings, vol. 3, pp. 236-240, 2018

ISSN 2466-4626 (online) | DOI: 10.21175/RadProc.2018.49

www.rad-proceedings.org

\title{
THE STUDY OF THE INFLUENCE OF ADDITIVES IN THE CRYSTALLINITY OF RECYCLED LDPE BY IR AND XRD ANALYSIS
}

\author{
B. Papajanı ${ }^{*}$, E. Vataj ${ }^{2}$, A.V. Hasımı ${ }^{3}$, A. Sinanaj4 \\ ${ }^{1}$ Faculty of Natural Science, University “Aleksander Xhuvani”, Elbasan, Albania \\ 2Institute of Applied Nuclear Physics, University of Tirana, Albania \\ 3Institute of Geosciences and Energy, Water and Environment, Polytechnic University of Tirana, Tirana, Albania \\ 4Faculty of Natural Science, University “Aleksander Xhuvani”, Elbasan, Albania
}

\begin{abstract}
In this study, the influence of additives used during the recycling process, to the crystallinity of LDPE was analyzed. The usage of LDPE recycled is growing, as well as other types of recycled plastics, due to its flexibility and other properties. The spectroscopic method of infrared vibration is used for microstructure analysis of the samples. The presence of low-intensity peaks to infrared spectrum at $1300-800 \mathrm{~cm}^{-1}$ for all samples indicates the presence of additives. The additives used in the recycled polymers influence their degree of crystallinity that is closely linked with their physical and mechanical properties. Due to the different rates of crystallinity the samples show different intensities of peak at $726 \mathrm{~cm}^{-1}$. XRD techniques are used to calculate the degree of crystallinity and to study the phase compound of recycled LDPE. Rutile's and calcite's peak were identified by diffractgrams analyses as the additives added in the recycled $L D P E$.
\end{abstract}

Key words: Crystallinity, microscopy, phase compound, polarized light, spectroscopic methods, $X$-Ray diffraction

\section{INTRODUCTION}

Polyethylene is the most widely used thermoplastic material and is composed of ethylene [1]. Polyethylene (PE) materials can be applied in many fields of life. Two important classes of PE materials are low density (LDPE) and high-density polyethylene (HDPE). LDPE is characterized by a relatively low rigidity and low degree of crystallinity. LDPE offers excellent clarity and easy processing. Therefore, it can be used as packaging material, e.g. foil, and as cover sheeting in many fields of daily and industrial life [1]. Recycling is one the main ways processing plastic materials, it constitutes one of the main problems of society including two important issues: solid waste management and environmental protection. Plastic recycling is both an economic and an environmental activity. Plastics recycling presents numerous technical, economical, and marketing challenges. One such technical issue is the variability of product composition and color, because discarded products are made from a wide array of resins and additives [2]. Infra Red spectroscopy is probably the most used spectroscopic methods in polymer science as is appropriate both in qualitative analysis as well as quantitative analysis of polymeric materials. Modern IR spectroscopy is a simple analysis method, and gives direct results. Using IR can identify unknown materials, to determine the quality or stability of a sample, monitor their production and processing, e.g. cross-link or crosssectional degree as well as determine the composition of a compound mixture [3].

The vibrational spectrum of a molecule is considered to be a unique physical property and is characteristic of the molecule. As such, the infrared spectrum can be used as a fingerprint for identification by the comparison of the spectrum from an "unknown" with previously recorded reference spectra. In the most basic terms, the infrared spectrum is formed as a consequence of the absorption of electromagnetic radiation at frequencies that correlate to the vibration of specific sets of chemical bonds from within a molecule [4].

Infrared Spectroscopy utilizes the fact that molecules absorb specific frequencies that are characteristic of their structure. These absorptions are resonant frequencies, i.e. the frequency of the absorbed radiation complies with the transition energy of the bond or the group vibrating [4]. A polymer can be considered partly crystalline and partly amorphous. The crystalline domains act as a reinforcing grid, like a composite material, and improve the performance over a wide range of temperature. The X-Ray Diffractometer (XRD) techniques are used successfully for the crystallographic study of polymers. It is used for analyzing crystalline phases, determining the extent of crystallinity and identifying crystalline structure [5]. Xrays are electromagnetic waves with a wavelength between 0.01 and $1 \mathrm{~nm}$, which, when incident on a

*papajanib@yahoo.com 
B. Papajani et al., The study of the influence of additives..., RAD Conf. Proc., vol. 3, 2018, 236-240

material, interact with electrons in the material and are scattered. X-ray waves scatter from different electrons and interfere with each other. This interference gives the resulting diffraction pattern, the positions of diffraction peaks and their relative heights, in which the intensities vary with scattering angle. X-rays scattered from the periodic repeating electron density of a perfectly crystalline material give sharp diffraction peaks at angles that satisfy the Bragg relation, whether the crystal consists of atoms, ions, small molecules, or large molecules. Amorphous materials will also diffract $\mathrm{X}$-rays and electron, but the diffraction is a much more diffuse, low frequency halo (the so called "amorphous halo") [5], [6].

Bragg derived Bragg's law for the distance $d$ between consecutive identical planes of atoms in the crystal:

$$
n \lambda=2 d \sin \theta
$$

where $\lambda$ is the $x$-ray wavelength, $\theta$ is the angle between the $x$-ray beam and these atomic planes and $n$ corresponds to the order of diffraction.

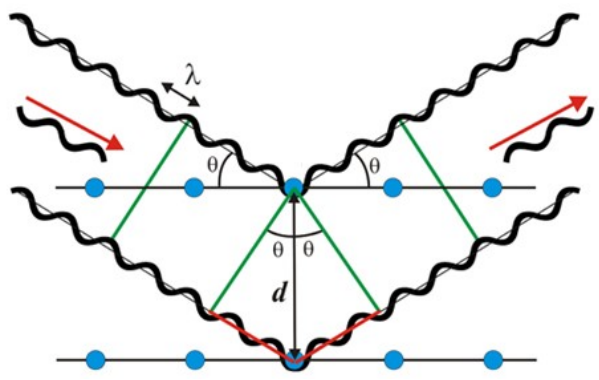

Figure 1. Principle of diffraction [6]

A general polymer x-ray spectrum will have a broad amorphous peak, and if the polymer has crystallinity, it will show up as sharp peaks on the top of large amorphous peak, as in the following figure.

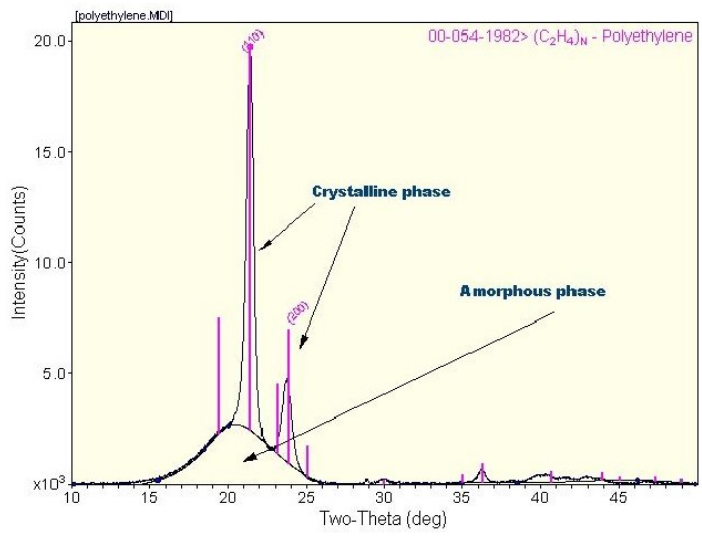

Figure 2. XRD pattern of Polyethylene [6]

The percentage of the polymer crystallinity can be determined from equation:

$$
\% \text { crystallinity }=\frac{\text { Area under crystalline peaks }}{\text { Total area underall peaks }} \times 100 \%
$$

\section{MATERIALS AND METHODS}

Samples used for this study are pure and recycled LDPE as granules and plastic bags. Pure LDPE is provided by Alfa Aesar GmbH \& Co KG. Recycled materials are provided by "Everest" Albanian company.

Table 1. List of samples

\begin{tabular}{|c|l|l|l|l|}
\hline No & Sample & Color & Shape & Usage \\
\hline $\mathbf{1}$ & $\begin{array}{l}\text { Pure } \\
\text { LDPE }\end{array}$ & $\begin{array}{l}\text { white } \\
\text { LDPE }\end{array}$ & microgranule & \\
\hline 3 & $\begin{array}{l}\text { Recycled } \\
\text { LDPE }\end{array}$ & Opaque & bag, granule & package \\
\hline 4 & $\begin{array}{l}\text { Recycled } \\
\text { LDPE }\end{array}$ & green & bag, granule & package \\
\hline 5 & $\begin{array}{l}\text { Recycled } \\
\text { LDPE }\end{array}$ & yellow & bag, granule & package \\
\hline 6 & $\begin{array}{l}\text { Recycled } \\
\text { LDPE }\end{array}$ & red & bag, granule & package \\
\hline 7 & $\begin{array}{l}\text { Recycled } \\
\text { LDPE }\end{array}$ & black & bag, granule & package \\
\hline
\end{tabular}

\subsection{Infra Red Spectroscopy}

The apparatus used is TJ270-30A Dualbeam Infrared Spectrophotometer. For the IR measurements are used, pure polyethylene and a wide range of recycled plastic bags LDPE, like thin films. The sizes of all samples are $4 \times 4(\mathrm{~cm})$, enough to cover the circular hole that allows infrared radiation to pass between the metal holder. The measurements of infrared spectra are optimized using the corresponding software of the apparatus and the results are processed on the Origin program.

\subsection{XRD Diffractometry}

X-ray diffraction patterns are measured at the Institute of Ceramics, Glass and Construction Materials, Freiberg, Germany with a X'PERT Pro MPDPW 3040/60 diffractometer from PANALYTICAL in transmission geometry. The qualitative phase analysis procedure involved the identification of major and minor phases using the X'Pert High Score Plus Software. The measurement conditions are as follows: angular range, $7.5<2 \theta<80{ }^{\circ}$ step size $0.013^{\circ}$, step time 30s, Copper radiation $\mathrm{Cu}$ (wavelength 1.540598 $\AA$ ), tube power $40 \mathrm{kV} / 40 \mathrm{~mA}$. XRD measurements are performed using recycled LDPE as granules. Small amount of granules of recycled LDPE in different colors is put on different microscope slides and each of them is melted in room conditions at LDPE melting point $\mathrm{T}_{\mathrm{m}}$ $=110^{\circ} \mathrm{C}$. For transmission measurement each melted sample is placed between two Kapton foils. The Kapton foil (the yellow one) does not affect the measurements. Thin plastic foil is fixed on a metal ring on which the sample is placed. Another plastic foil is placed above the sample. A second metal ring with a larger diameter than the first ring is used to fix the sample. 
B. Papajani et al., The study of the influence of additives..., RAD Conf. Proc., vol. 3, 2018, 236-240

\section{RESULTS AND DISCUSSION}

\subsection{IR characterization}

IR spectroscopic measurements are performed for all plastic bag recycled LDPE samples.

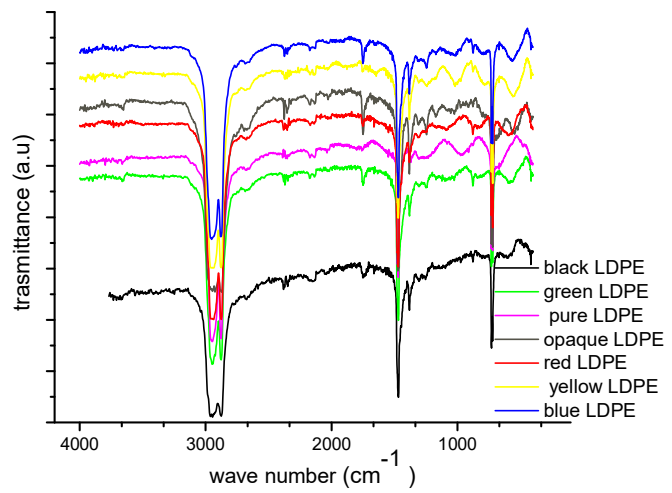

Figure 3. IR spectra of all plastic bag samples vertically shifted

The transmittance of black recycled LDPE is significantly lower than other samples. All recycled plastic bags LDPE samples display three characteristic groups of pure LDPE peaks respectively to the wave numbers: $2920-2850 \mathrm{~cm}^{-1}, 1490-1420 \mathrm{~cm}^{-1}$, 750 to 720 $\mathrm{cm}^{-1}$ [3]. All recycled samples are composed of pure LDPE. Peaks displayed wavelengths to above bands are the absorption peaks of $\mathrm{C}-\mathrm{H}$ and $\mathrm{C}-\mathrm{C}$ connections belonging to the main chain of polyethylene at infrared area. [4],[7]. The peak at the $2920-2850 \mathrm{~cm}^{-1}$ band, is attributed to $\mathrm{CH}_{2}$ groups. The peak shown at the wave number $1460 \mathrm{~cm}^{-1}$, is dedicated to the scissors bending of $\mathrm{CH}_{2}$ groups and the peak at $1303 \mathrm{~cm}^{-1}$ belongs to amorphous area polymer. Low-intensity peaks in the area of $1300-800 \mathrm{~cm}^{-1}$, indicate the presence of additives for all recycled LDPE samples [4], [7], [8]. The peak at $726 \mathrm{~cm}^{-1}$, represents a rocking frequency of the $\mathrm{CH}_{2}$ group in planar zigzag chain and is indicative of the crystals' existence. In the zone of $726 \mathrm{~cm}^{-1}$ all samples exhibit different intensities peak, which indicate different percentages of their crystallinity.

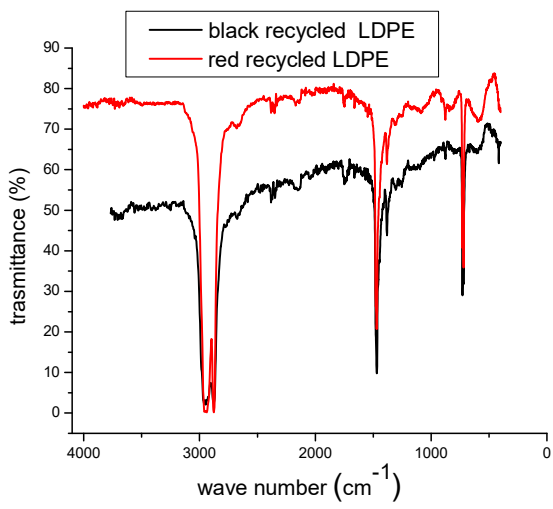

Figure 4. IR spectra for black and red plastic bags recycled LDPE
From Figure 4, red plastic bag recycled LDPE sample has the highest intensity of peak and black sample has the lowest one compared to other samples.

\subsection{XRD characterization}

In Figure 6, diffractograms of red and black granule recycled LDPE as representatives of highest and lowest crystallinity are presented. The diffractogram of pure LDPE in Figure 5 is presented to be compared with recycled material.

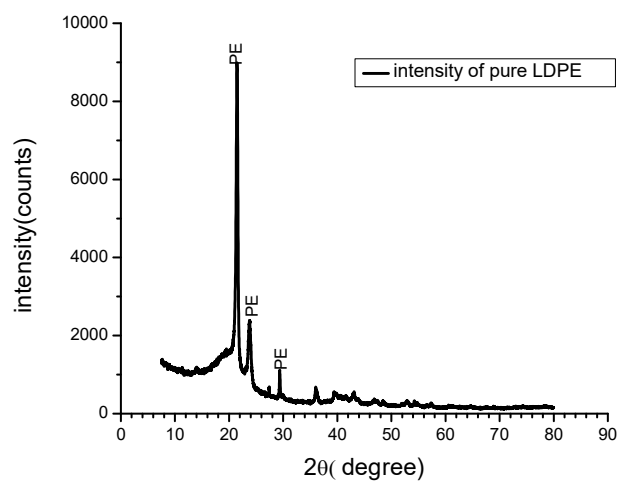

Figure 5. XRD pattern of pure LDPE

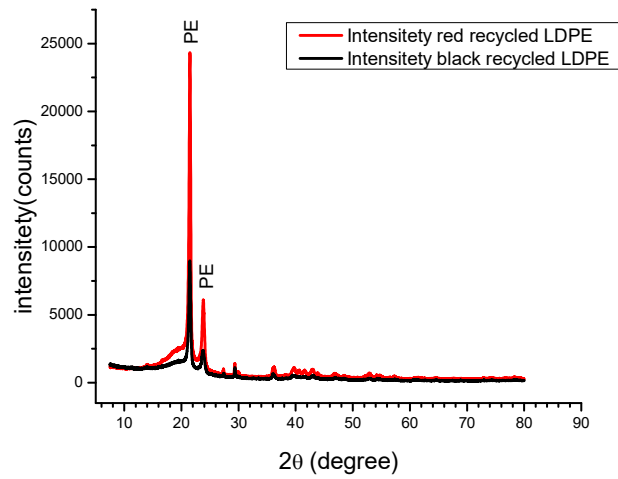

Figure 6. XRD pattern of red and black recycled LDPE granules

Diffractograms obtained experimentally for all LDPE samples indicate that pure and granule recycled material is a semi crystalline polymer. The crystalline parts give sharp narrow diffraction peaks and the amorphous component gives a very broad peak. It is observed in all diffractograms of recycled LDPE the appearance of two characteristic peaks of polyethylene $\left(\mathrm{C}_{2} \mathrm{H}_{4}\right)$, as the main compound, at $2 \theta$ angles of $21.73^{\circ}$ and $24.18^{\circ}$ respectively. By the analysis of phase compound using the X'Pert High Score Plus Software, is identified the presence of rutile $\left(\mathrm{TiO}_{2}\right)$ and calcite $\left(\mathrm{CaCO}_{3}\right)$ peaks to all recycled samples [9]. This presence is confirmed also with the calculation of the interplanar spacing (d-spacing) using experimental data and Bragg's law. 
B. Papajani et al., The study of the influence of additives..., RAD Conf. Proc., vol. 3, 2018, 236-240

Table 2. Qualitative analysis of X-ray

\begin{tabular}{|c|c|c|c|c|}
\hline Peak & $2 \theta$ & $\begin{array}{c}\mathbf{d}_{\text {hkl }} \\
(\boldsymbol{\AA})\end{array}$ & $\begin{array}{c}\mathbf{I} \\
\text { (impuls/s) }\end{array}$ & phase \\
\hline 1 & 21.73 & 4.090 & 9056 & $\mathrm{PE}$ \\
\hline 2 & 24.18 & 3.681 & 2388 & $\mathrm{PE}$ \\
\hline 3 & 27.41 & 3.25 & 1343 & $\mathrm{TiO}_{2}$ \\
\hline 4 & 29.33 & 3.04 & 1548 & $\mathrm{CaCO}_{3}$ \\
\hline
\end{tabular}

Finely powdered rutile (Titanium dioxide) is the most important white pigment used in the polymer industry thereby imparting whiteness, brightness, and opacity when incorporated into a plastic product. It is widely used because it efficiently scatters visible light, thereby protecting the polymer from UV degradation [9]. Calcite is a rock-forming mineral with a chemical formula of $\mathrm{CaCO}_{3}$. Powdered calcite is often used as a white pigment or "whiting". $\mathrm{CaCO}_{3}$ may be white or in different colors and can be used as coloring pigment in polymers. The presence of calcium carbonate provides the maintenance of transparency in polymer, keeps unchanged optical properties of the polymer, increases plastic resistance against light and high temperatures and enables no change of color of plastic under the influence of UV (Ultra Violet) [9]. There are observed by diffractograms, different intensity values of the main peak at different samples. This indicates that samples have different amounts of additives and thus represent varying degrees of crystallinity. Additives added during recycling process influence the crystallinity degree [9], [10]. By processing raw experiment data for each sample, the dependence of intensity vs. $2 \theta$ angle data, in the range of $14^{\circ}<2 \theta<26^{\circ}$ angles and the fitted multiply peaks curve, is presented to determine the degree of crystallinity.

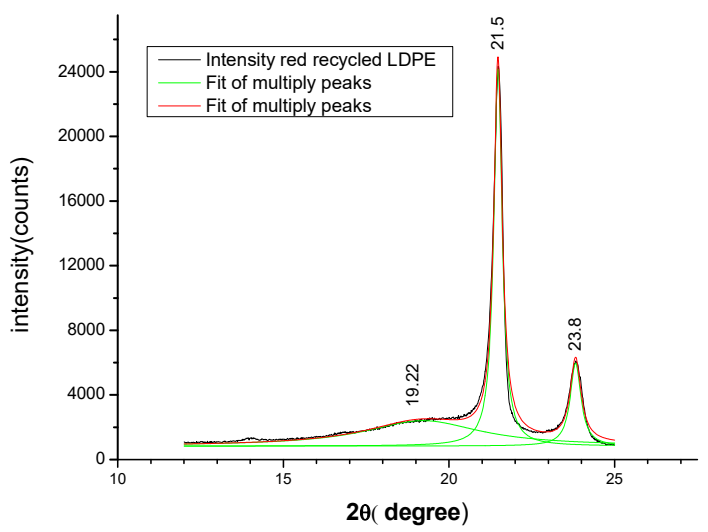

Figure 7. Intensity vs. $2 \theta$ angle data, in the range of $14^{\circ}<2 \theta<26^{\circ}$ and the fitted multiply peaks curves of recycled LDPE (red).

The degree of crystallinity for all granule recycled samples and for pure LDPE sample are calculated. The results are presented in Table 3 .

As it is seen from Table 3, the LDPE samples have different degree of crystallinity. LDPE (black) has the lowest degree of crystallinity and the red one has the highest from the recycled polymers. The samples have different amounts of additives and thus represent varying degrees of crystallinity. Additives added during recycling process influence their crystallinity degree [10].

Table 3. The area under crystalline and amorphous peaks and the degree of crystallinity for all LDPE samples

\begin{tabular}{|l|c|c|c|c|c|c|c|}
\hline \multicolumn{1}{|c|}{ LDPE } & Pure & Black & Blue & Opaque & Green & Red & Yellow \\
\hline $\begin{array}{l}\text { Area } \\
\text { amorphous } \\
\text { peaks }\end{array}$ & 12033 & 20197 & 2020 & 13410 & 15748 & 10423 & 13684 \\
\hline $\begin{array}{l}\text { Area } \\
\text { crystalline } \\
\text { peaks (I) }\end{array}$ & 3165 & 6100 & 8000 & 10442 & 4543 & 11172 & 4913 \\
\hline $\begin{array}{l}\text { Area } \\
\text { crystalline } \\
\text { peaks (II) }\end{array}$ & 771 & 1900 & 3008 & 3198 & 1279 & 3163 & 1403 \\
\hline $\begin{array}{l}\% \\
\text { crystallinity }\end{array}$ & 25 & 28 & 40 & 50 & 35 & 58 & 32 \\
\hline
\end{tabular}

\section{CONCLUSION}

XRD and IR methods used in this paper confirmed the existence of additives in all recycled LDPE samples as granules and plastic bags. The percentages of crystallinty in granule recycled of LDPE samples are calculated using XRD method because it measures long-range order or intermolecular order as a result of chain packing. IR measures short-range order,_so it is a supporting method. All recycled LDPE samples display three characteristic groups of pure LDPE peaks. Recycled LDPE does not have fundamental structural changes from pure LDPE. All plastic bag recycled samples exhibit different intensities peak at $726 \mathrm{~cm}^{-1}$, which indicates a different percentages of their crystallinity.

Recycled LDPE is a semicrystalline material. By the qualitative analysis are identified the presence of rutile $\left(\mathrm{TiO}_{2}\right)$ and calcite $\left(\mathrm{CaCO}_{3}\right)$ peaks at all granule recycled samples. Additives added improve polymer crystallinity and its physical properties LDPE samples have different degrees of crystallinity due to different amounts of additives into them.

\section{REFERENCES}

1. M. Chanda, S. K. Roy, Industrial polymers, specialty polymers and they applications, 4th ed., Boca Raton (FL), USA: Taylor \& Francis, 2007.

DOI: $10.1201 / 9781420080599$

2. Y. Zare, "Recycled Polymers: Properties and Applications," in Recycled Polymers: Properties and Applications, vol. 2, V. K. Thakur, Ed., Shrewsbury, UK: Smithers Rapra, 2015.

Retrieved from: https://www.smithersrapra.com/Sm ithersRapra/media/Sample-Chapters/RecycledPolymers-Properties-and-Applications,-Volume2.pdf;

Retrieved on: Apr. 23, 2018

3. S. Krimm, C. Y. Liang, G. B. B. M. Sutherland, "Infrared Spectra of High Polymers. II. Polyethylene," J. Chem. Phys., vol. 25, no. 3, 549, 1956.

DOI: $10.1063 / 1.1742963$ 
B. Papajani et al., The study of the influence of additives..., RAD Conf. Proc., vol. 3, 2018, 236-240

4. J. Coates, "Interpretation of Infrared Spectra, A Practical Approach,” in Encyclopedia of Analytical Chemistry, Chichester, UK: John Wiley \& Sons, 2000, pp. 10815 - 10837.

DOI: $10.1002 / 9780470027318$

5. L. E. Alexander, X-Ray Diffraction Methods in Polymer Science, New York (NY), USA: John Wiley and Sons, 1969.

6. V. Hauk, "Structural And Residual Stress Analysis By X-Ray Diffraction On Polymeric Materials And Composites," Advances In X-Ray Analysis, vol. 42, pp. $540-554,2000$.

Retrieved from: https://pdfs.semanticscholar.org/19 f7/7d2aa7b5eeb512fo9142566d3of4c968b1ec.pdf; Retrieved on: Apr. 23, 2018

7. J. Florestan, A. Lachambre, N. Mermilliod, J. C. Boulou, C. Marfi, "Recycling of plastics:
Automatic identification of polymers by spectroscopic methods," Resour. Conserv. Recycl., vol. 10, no. 1-2, pp. 67 - 74, Apr. 1994 DOI: $10.1016 / 0921-3449(94) 90039-6$

8. N. J. Everall, J. M. Chalmers, P. R. Griffiths, Vibrational Spectroscopy of Polymers: Principles and Practice, Chichester, UK: John Wiley \& Sons Ltd, 2007.

9. C. Klein, C. S. Hurlbut, Manual of Mineralogy, 2oth ed., New York (NY), USA: John Wiley and Sons, 1985 .

10. F. P. La Mantia, "Plastics Additives," in Recycled plastics: additives and their effects on properties, London, UK: Chapman and Hall, 1998, ch. 59, pp $535-543$

DOI: $10.1007 / 978-94-011-5862-6 \_59$ 